\title{
Diminuição do tempo para desospitalização em pacientes com indicação de home care
}

Autores: Renata Puzzo Bortoleto, Silvia Castro

Caruso Christ, Adriana das Neves Louro, José Lúcio Maito Correa, Mario Antonio Torezan Filho 


\section{BP Mirante - 2018}

\section{$\checkmark 120$ leitos}

$\checkmark 20$ leitos UTI/ 10 semi/ 10 UCI

$\checkmark 7$ salas cirúrgicas - 5057

cirurgias

$\checkmark 10.312$ atendimento PA

$\checkmark$ Média permanência 5,5 ; índice giro 4,3

$\checkmark$ Mortalidade 3,2\%
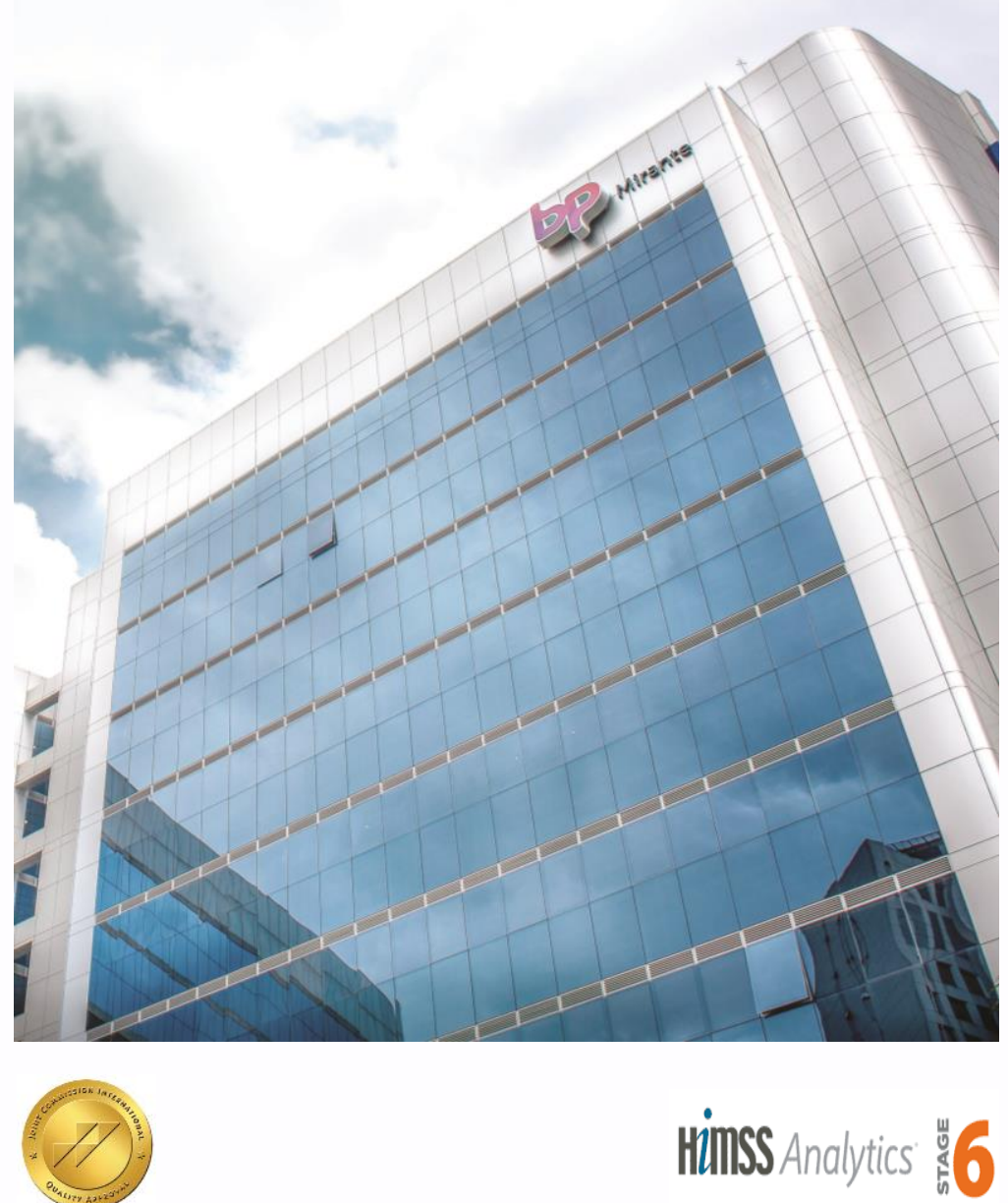


\section{Introdução}

Tempo de internação

Riscos de eventos adversos e morbimortalidade

Processo de Solicitação de Home Care:

- Fragmentado

- Número excessivo de pessoas envolvidas (diversos cargos)

Desconhecimento de responsabilidades e atribuições

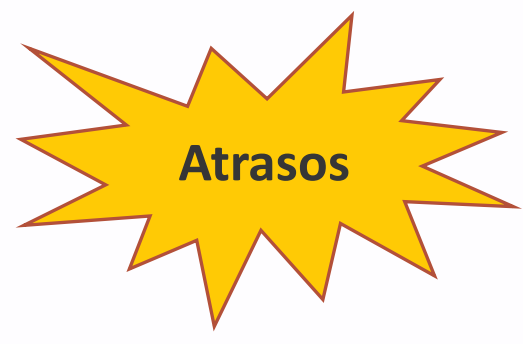

A Beneficência Portuguesa de São Paulo
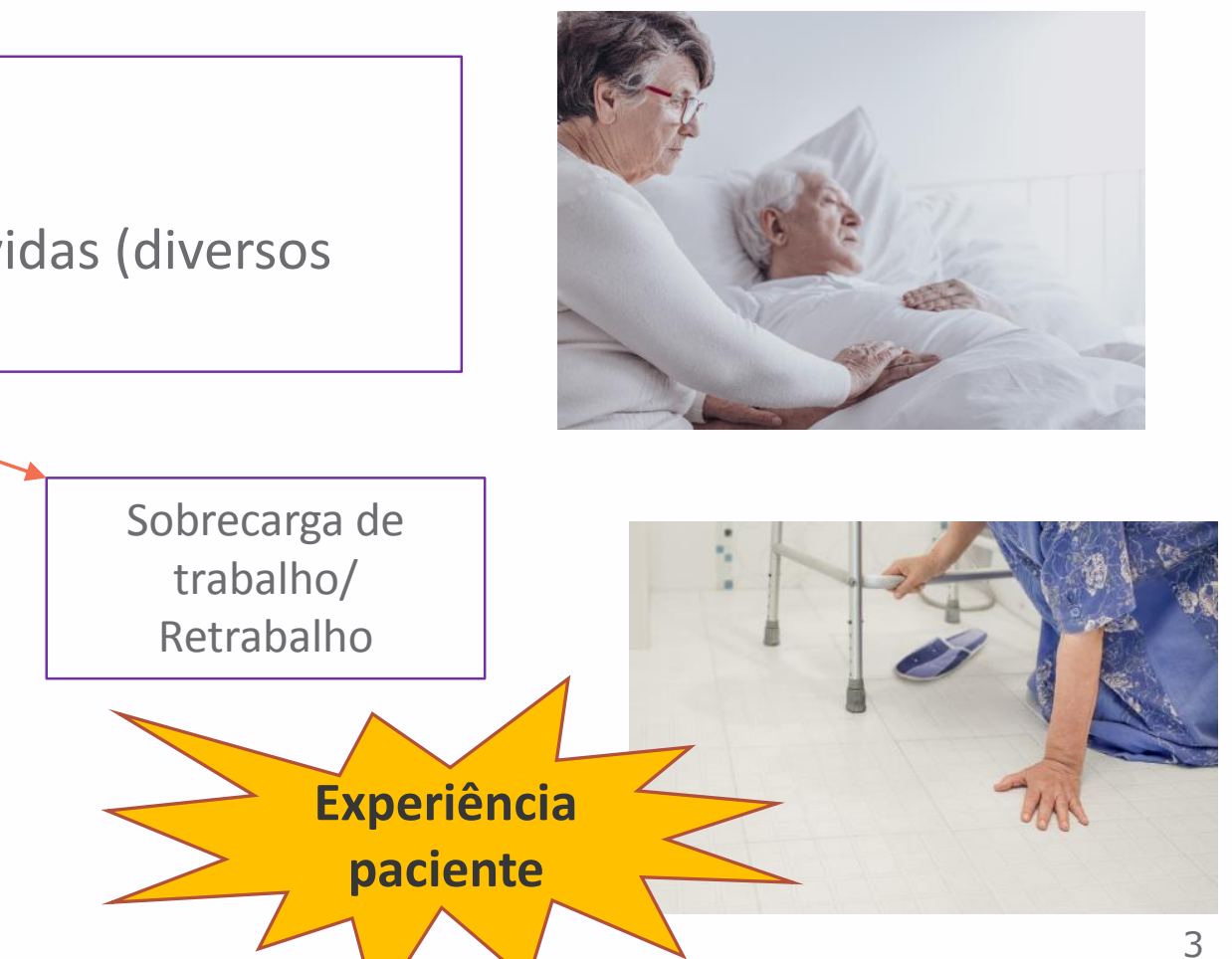

https://proceedings.science/p/112338?lang=pt-br 


\section{Objetivo: Reduzir o tempo para desospitalização de pacientes}

com indicação de home care.

\section{Método: Mapeado processo e oportunidades de melhoria em} cada etapa e elaborado plano de ação:

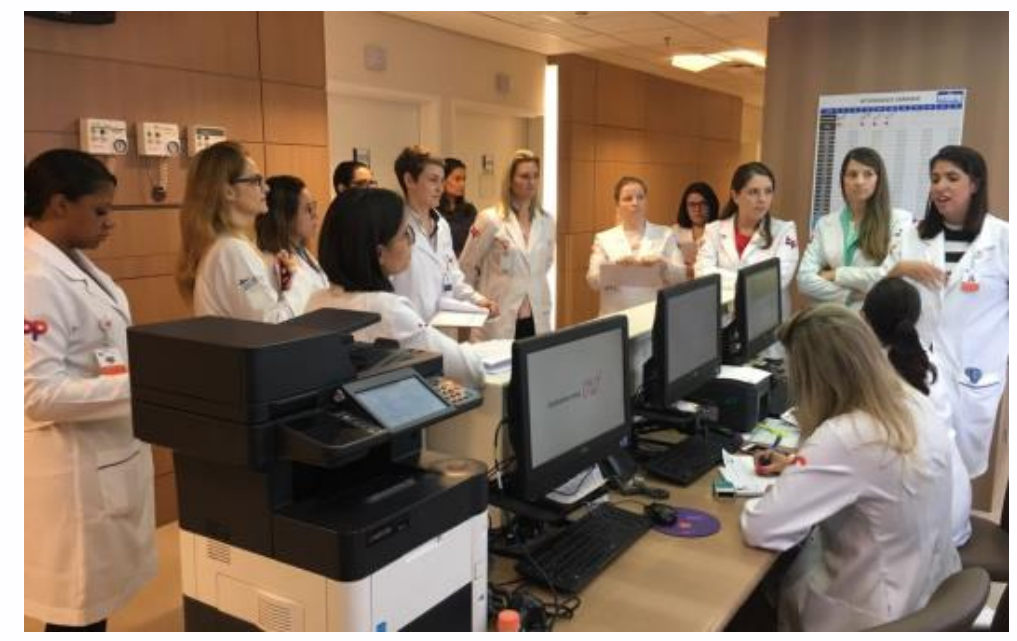




\section{Home Care - problemas mais frequentes}

- Pedidos de Home Care incoerentes com condição clínica

- Home Care liberado e família/paciente não aceita alta

- Alta hospitalar no dia do pedido de Home Care

- Dificuldades para intercâmbio de informações

- Ausência de controle de entrada do enfermeiro captador

- Falta de informações sobre previsão de alta

Médicos desconhecem deveres da família e da operadora; fluxo Home Care; Equipe não comunica/envolve família

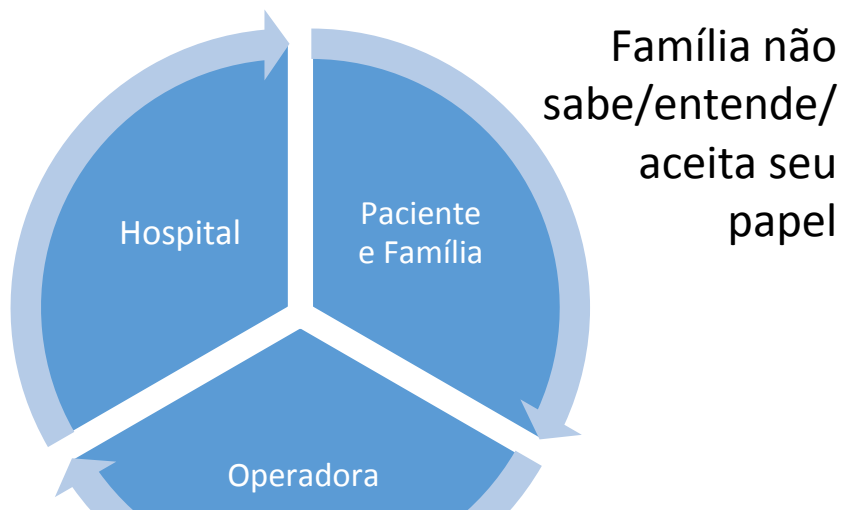




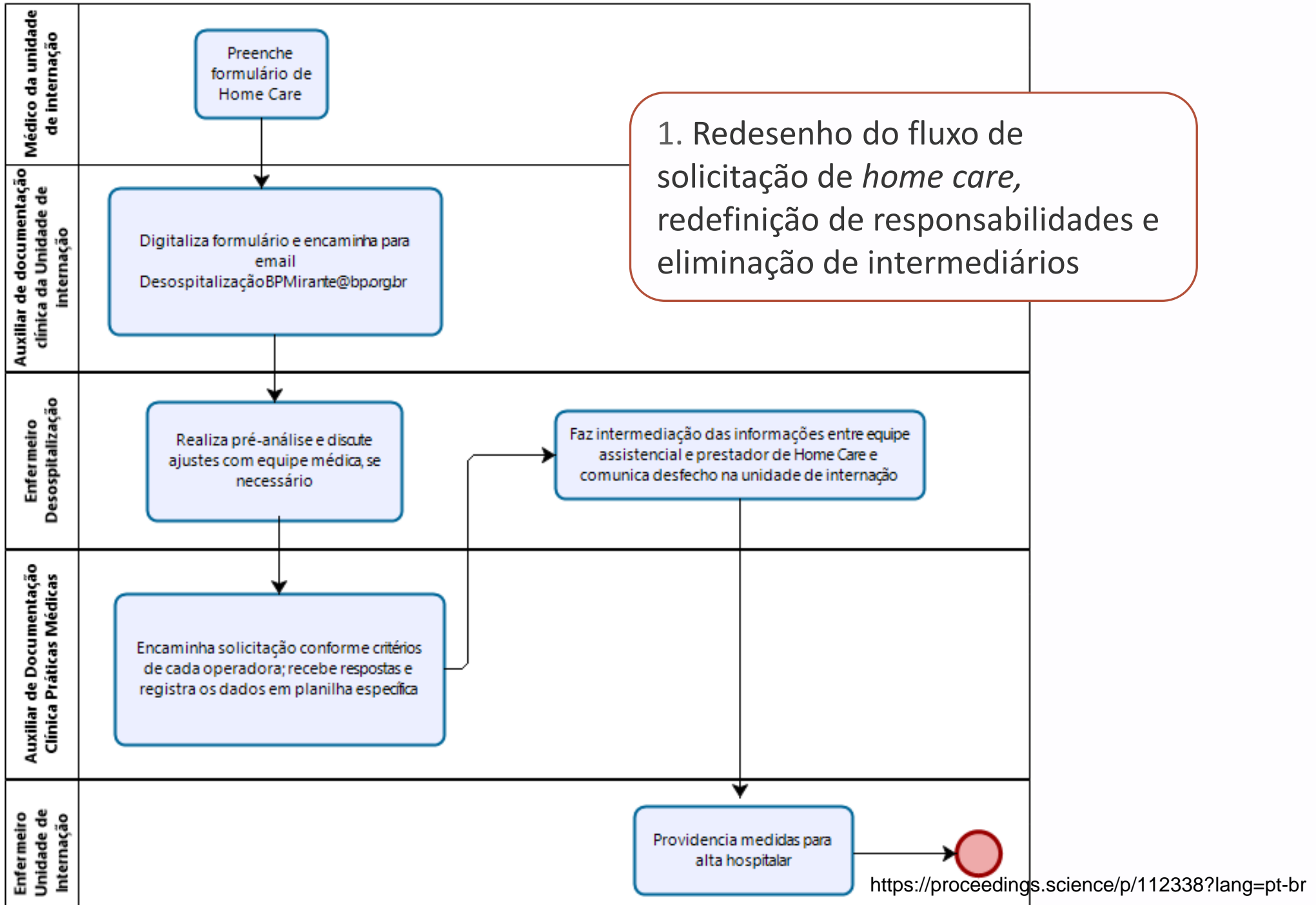


2. Análise semanal dos pacientes em longa permanência, antecipação de necessidade de home care

3. Sistematização do acompanhamento dos pacientes

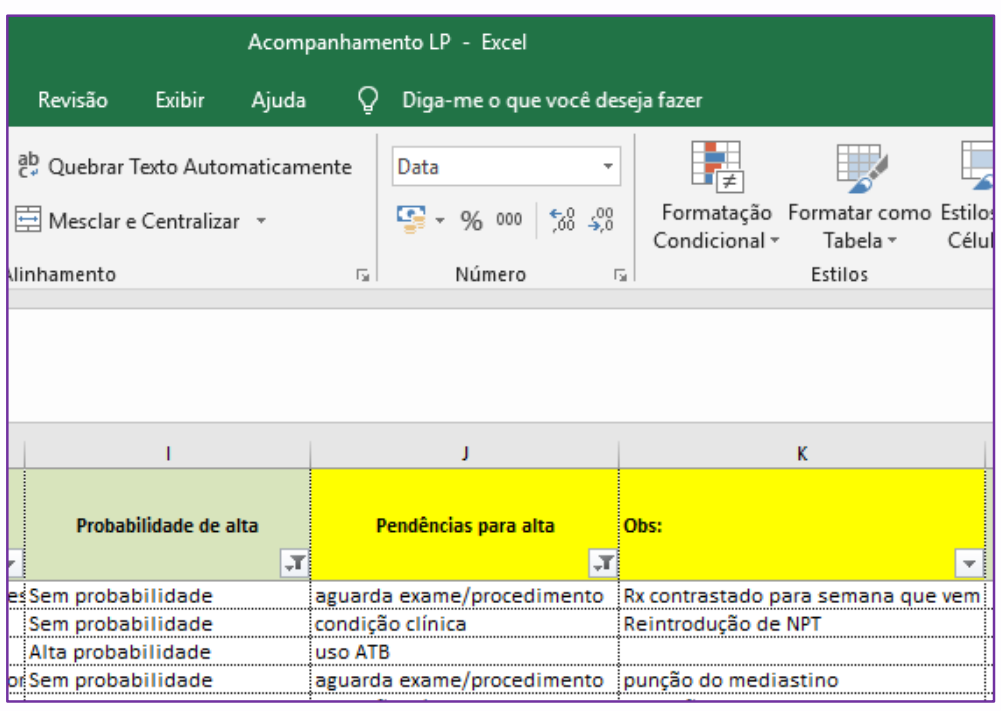

A Beneficência Portuguesa de São Paulo
4. Padronização da solicitação de home care (formulário)

\begin{tabular}{|c|c|c|}
\hline \multicolumn{3}{|r|}{$\begin{array}{l}\text { Colar etiqueta ou preencher: } \\
\text { Nome: } \\
\text { NA: } \\
\text { Leito: }\end{array}$} \\
\hline \multirow{2}{*}{\multicolumn{3}{|c|}{ 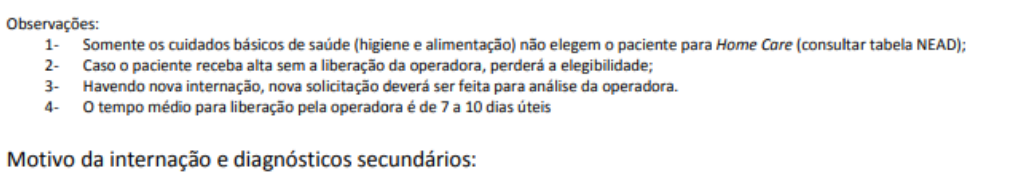 }} \\
\hline & & \\
\hline \multicolumn{3}{|l|}{ Situação do Paciente } \\
\hline 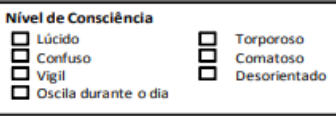 & 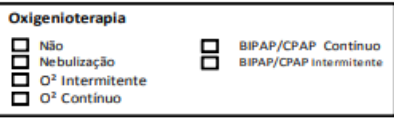 & $\begin{array}{l}\text { Alimentaç̆o } \\
\text { 吕 Oral } \\
\text { Parenteral } \\
\text { Enteral }\end{array}$ \\
\hline
\end{tabular}

5. Evolução padronizada em prontuário 6 . Reestruturação do grupo de e-mails ( 22 $\rightarrow 5$ )

7. Alocação de enfermeira dedicada ao processo de desospitalização

8. Plano de comunicação 


\section{Resultados}

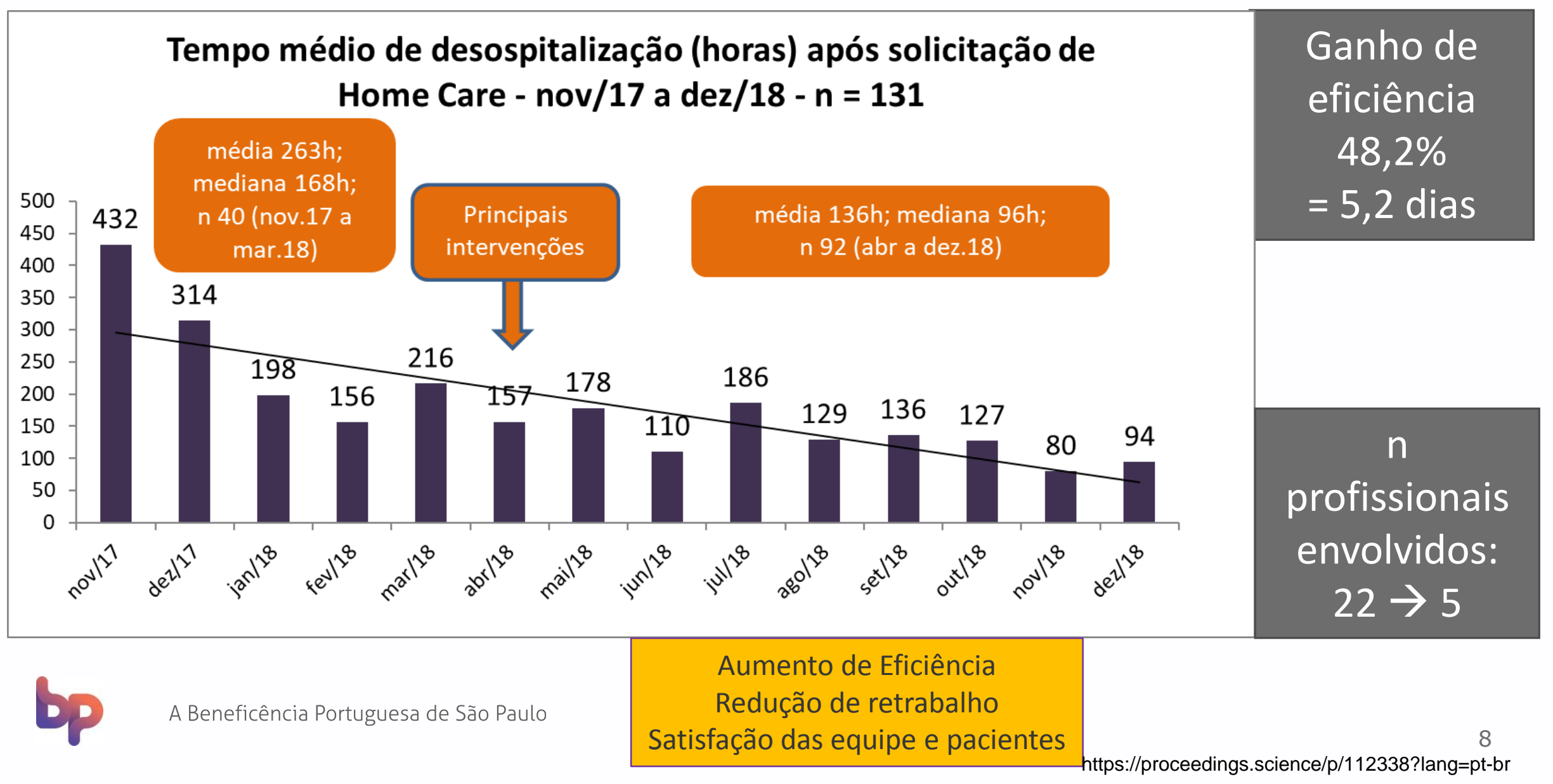




\section{Conclusões e perspectivas}

- Maior segurança no processo de desospitalização

- Sistematização do planejamento de alta

- Eficiência no gerenciamento de leitos

- Aumento do giro de leitos e diminuição da média de permanência hospitalar

- Melhor experiência para paciente e cliente médico

Fatores Críticos de Sucesso:

- Comunicação eficiente

- Definição de responsabilidades

- Capacidade adequada da equipe de Desospitalização 


\section{A Beneficência}

Portuguesa de São Paulo

\section{Obrigada!}

